\title{
Editorial Suffering in Contemporary Society
}

\author{
Alfred Bordado Sköld (1) \& Peter Clement Lund \\ Aalborg University, Department of Communication and Psychology, Teglgårds plads 1, 9000 \\ Aalborg,Denmark(alfred@hum.aau.dk; pclund@hum.aau.dk)
}

Suffering points in every direction. It unites and separate us, makes us feel alive, yet close to death. Suffering makes us hide and act, love and kill. From the primal scream of the newly born to the oftenpainful last sip of air that we breathe, suffering pervades our entire lives. We feel it through the core nerve of our being, and suffering, in Kierkegaard's words, "nails us to ourselves". There is nowhere to hide and yet there is. The world was always one of others and through them, our lives acquire its form and its bearing. Yet these others cannot be trusted; they betray, grew old, sick and finally, they too must die. The relational shields that protect and mark who we are can alleviate but not protect us from suffering. As Løgstrup (1997) has suggested, it is through the irrevocable unshareability of suffering that the need to attest our inner experiences and articulate these through language or action emerges. It is thus the solitude of suffering that creates the active need to connect with others, and on the one hand, we find ourselves, with Alphonso Lingis' (1994) words, in "the community of those who have nothing in common". On the other, riots and revolutions often testify to the potential of suffering to unite across the borders that otherwise tends to diverge us.

As Martin Hägglund (2019) has pointed out, all of us find ourselves thrown into a world that leaves much to wish for - none of us have asked for this life, and yet we are asked to carry it; to "own our lives”. Mental states are never identical to brain states (Kripke, 1980) and the agonies that humans undergo always point to us as spiritual beings, to suffering being more than pain. Shortly after the world has begun to make sense, reflexivity kicks in and we all become, as Augustine puts it in his Confessions, "questions unto ourselves". Being human means experiencing that - while our actions are earnest attempts of responding to these questions, final answers remain out of reach, and we find 
ourselves, like the Neurath's sailor, forced to rebuild the ship on open sea without any land in sight. Until the ship suddenly sinks one day and we are no more.

At times, the lack of answers that a cold and callous cosmological chaos leaves us to fathom, might make one wonder whether there is any point in continuing. The capacity to end life through suicide is one of the features - together with our persistent need to bury our dead, that mark our species. As human beings, we have the capacity, not only to suffer, but to "curse the day we were born". There are no astral laws that guarantee human existence and we often ask ourselves why. The existential version of Leibniz's question why there is something rather than nothing, reads: Why am I? (O'Byrne, 2010). With what right do I occupy this place on planet earth? Who grants me this life, this air, this sun and this love? Or, conversely, but not unrelatedly: Who cursed me to this hell? More often than we are willing to admit, we find ourselves as abandoned children, deadly aware of the fact that we are not the source of our own existence, and yet still unable to find someone or something willing to claim responsibility, not only for who we are, but that we are.

Throughout the Twenty-first century, we have begun to ask these questions on a global level. The superego of today breathes $\mathrm{CO} 2$ and we are beginning to confront ourselves with questions such as: With what right do we occupy the earth and by what right do we demolish it in the way we are doing? If the evils of the Twentieth century - in Isiah Berlin's words, "the most terrible century in human history" - made it unquestionably clear that we carry all the necessary potential to eradicate ourselves, the present century has proven that we likewise are to be held accountable for climate change, an accelerating ecological crisis and the extinction of species and entire eco systems. In the time of the Anthropocene, the planet aches, and these predicaments inevitably raise the question of which kinds of sufferings should be endured and which kinds should be revolted against. Not all forms of suffering call for stoic equanimity or fatalism. Many of the social pathologies that pervade our epoch need not to be met as phenomena that are naturally given - the proliferation of contemporary malaises, mental illness', diseases, and psychosomatic disorders might, to a large extent, be related to social and cultural changes and upheaval (Keohane \& Petersen, 2013); they are pathological forms of development of society that lead to individual suffering and therefore they are also subject to change. Suffering is an inherent facet in human life, but it is also socially distributed, experienced, instigated and fought. Not all forms of suffering we see today are the same as we saw 100 years ago, simply because the social and cultural context under which suffering occurs has transformed through the course of history. 100 years ago, the ecological crisis was not on the mind of society and thus the suffering caused, either in the form of habitats being destroyed, humans 
displaced by weather related catastrophes or even the rise in psychological problems related to the loss of nature, was non-existent. Likewise, things like social media did not exist and no one killed themselves because of it. Thus, suffering changes, but it does not disappear. As such, suffering has been a main focus point for sociology and social theory since its inception: Durkheim described anomie and its effects on suicide rates - how the loss of a coherent collective consciousness led to suffering for individuals; Weber's thought on the disenchantment of the world and its rationalizing tendencies as an iron cage that made life less collective and less magical, which of course led to increased suffering; Marx's attention to the plight of the working class and their subjugation into the capitalistic system, which turned individuals into commodities and destroyed both their lives and the world they inhabited; and to Simmel's description of the tragedy of modernity and the effects of citylife on individuals.

From these classics and until now suffering has been on the mind of sociology. This means that many contemporary forms of suffering are forms of social suffering - they are caused by or born out of our social environment and each specific time-period creates new forms of suffering. Following the likes of Zygmunt Bauman or Peter L. Berger and Thomas Luckmann (Bauman, 1992; Berger \& Luckmann, 1966) one might say that much of what we call society and culture could be understood as ways of handling suffering - of staving off meaninglessness, pain and disorder. Thus, society like life itself - is built on suffering. Suffering is not a condition that one day could cease to exist, as a result of our conquering or overcoming it. Instead, we can understand the world today as continuously marked by new forms of suffering. In this way, we might come to see culture and suffering as existing in a dialectic relation - society is a response against suffering, that in turn creates new forms of suffering. We see this in the rise of psychiatric diagnoses - which has been described as a diagnostic culture (Brinkmann \& Petersen, 2015) where the increase in diagnostic classifications is meant to alleviate suffering, but simultaneously paves the way for new forms of suffering by removing our ability to talk about or understand suffering with any other form of language than a diagnostic one (Brinkmann, 2014).

Likewise, we may see many of the ailments of our current age as byproducts of our need to control and alleviate suffering. As Hartmut Rosa has recently described (Rosa, 2015) we live in an age of increasing acceleration of all parts of social life, personal life and technology - things that bear with them the promise of something better, of a life that might be easier and more fulfilling. As Rosa argues acceleration is the eudaimonic promise in contemporary society; a promise that a life lived to the fullest is a life free from suffering. But this has only lead to an increase in suffering in the forms 
of alienation and burn-out - to a mute and hostile world around us that removes our possibilities of a good life (Rosa, 2019). Acceleration of life and society promises to make things easier and to further our 'reach' into the world, making our lives better by freeing more time, but the promise fails. The faster we move and the more we want to further our control and reach, the less resonant experience we acquire. Thus, acceleration promises to relieve suffering - to give us more free time and give us more possibilities - but instead it causes more suffering in the form of complete alienation from a world that becomes illegible and incoherent for us. When we turn our attention to the impending ecological crisis, the story is much the same. Technology and capitalism made possible the increase in living standards for many, but also paved the way for the exploitation of individuals all over the world and led to new forms of suffering. Now, we are all facing the destruction of our planet at our own hands and the suffering this is already causing and in time will cause. This form of suffering has been created by ourselves, by the lives we have led and the culture we have been a part of - we have all done our part to help along the destruction of our habitats in what others have called the Capitalocene (Moore, 2017, 2018) - we are not just living in the Anthropocene 'The Age of Man', instead it might be argued that we are living in the Capitalocene. 'The Age of Capital' over the past five centuries has not just been about maximizing the productivity of labour-time, but also about maximizing the output of nature (Moore, 2018, p. 237). Thus, humans have created the system that causes their own suffering through the exploitation of both themselves and the places they inhabit.

Therefore, when we talk about suffering, we are talking about ourselves. About why the forms of suffering we experience have come to be and we come to question why they are still allowed to exist. Focusing on suffering is a way of reminding ourselves of who we are and who we want to be. This work is never done precisely because suffering and society exist in a constant tug-of-war where each new form of progress creates new suffering, and this suffering instigates new cultural replies to it. There is no real utopian world without suffering, but it might be worth imagining such a utopian world so we can strive for less suffering - aware that we cannot remove this existential condition, only lessen it and perhaps remedy its unequal distribution.

In light of this contemporary malady, the editorial board at Qualitative Studies has invited scholars from various academic fields to contribute to a deeper understanding of the questions, dilemmas and aporias that pervades our time. The idea has grown out of the interdisciplinary work in the research centre The Culture of Grief, where we are both Ph.D.-fellows. As a continuation of an earlier research project on Diagnostic Cultures (Brinkmann \& Petersen, 2016), the ambition of this centre has been to "grasp the many facets of grief, both in order to achieve a thorough comprehension of the 
phenomenon, but also in terms of being able to take a qualified position of the diagnosis and treatment of grief in order to improve community services to people in grief"' (The Culture of Grief, p. 2). Grief, which exists in the borderland between the existential universal and culturally specific, is, needless to say, a profound form of suffering. In grief, “one finds oneself fallen” (Butler, 2006, p. 21); we are forced to reckon with a the radicality of finitude and more prone to empathize with the suffering of the world. This special issue is our first attempt of expanding the notion and range of suffering beyond grief, hopefully pointing ahead to future projects and cooperation.

In various ways, the different contributions to this special issue attest to the important role of academia concerning how to come to terms with the various forms of suffering in our age. While some articles insist that adequate forms of suffering are left little or no room in a society that evades many forms of negativity, others make an argument that to remedy what is seen as unwarranted forms of suffering, action is called for. In order to draw this very distinction, intellectual work must be done, and this special issue offers some fruitful contributions that take this poignant task rather seriously. With articles from scholars near and far working within the fields of philosophy, sociology, psychology, anthropology and cultural studies, we are proud to present this special issue on suffering in contemporary society. Only after launching the project did we realize that "Social Suffering in Contemporary Society" is the subtitle of Pierre Bourdieu and coworkers' The Weight of the World, published in 1999. We carry no aspirations of being worthy followers of this masterpiece, but given that the weight of the world remains unequally distributed, and given that every era has its specific burdens, the struggle most go on. And "there is never time to wait" (Hägglund, 2019, p. 389). "A generation share time", Lisa Barrister (2017) writes, and we suggest that suffering is one of the most prominent features of sharing time, that is, of belonging to a generation. There is little reason to remind our readers of the potential of suffering to tear individuals, groups, countries and the entire world apart, open the gates to hell and what is worse. What is more imperative is the potential of suffering to heal and unite, to call for mutual recognition, respect and solidarity. The sufferings of our contemporary societies offer a key to understanding who we are, inspiration for the struggles to become someone else and fuel for action in that direction.

To guide our readers throughout this tour de force throughout the land of agony, a short presentation of the articles will now follow. 
In 'Forced adulthood': An aspect of 'quarterlife crisis' suffered by young English and Assemese adults, Raginie Duara, Siobhan Hugh-Jones and Anna Madill discuss the transition into adulthood for young people. Through a qualitative study they investigate the suffering that occurs through the, sometimes, traumatizing effect of having to assume adult responsibilities. By using methods such as photo-elicitation and time-line interviews with 22-30-year-olds from both England and Assam, India, they elucidate how this form of suffering is mediated and shaped by a person's cultural and educational background. They discuss how this form of quarterlife crisis is different from the more commonly known midlife crisis, by being characterized by feelings of unpredictability and apprehension. The article also discusses how this notion of forced adulthood plays out differently in the two countries - one being more individualistic and less traditional and the other more traditional and collectivistic. They describe three sub-themes from their research: (1) The feeling of being rushed into financial self-sufficiency, (2) the notion of training oneself to be an adult and the inherent chrononormativity in this, and (3) The relentless responsibilities of being 'the man in the house'.

In Mothering Death: A Psychosocial Interpretation of Breast Cancer Biography, Birgitta Haga Gripsrud investigates the intrapsychic and social conflicts related to breast cancer, drawing on a single-case study with a 50-year-old woman having her breast transplanted as part of cancer treatment. The statement "I would rather die than lose my breast" becomes the opening to an article that - with a point of departure in vivid empirical material, raises fundamental questions of the meaning of breasts, tumors and life as such. In the wake of COVID-19, cancer might have temporally, lost part of its status as the plague of our time, but this disease still affects all of our lives at some point. Drawing on earlier research on the cultural significance of breasts and femininity, Gripsrud makes it undeniably clear that despite the fact that cancer is close to a universal existential, it matters whether is strikes one part of the body or another. Furthermore, the meaning of cancer, that in this article is exhibited through group interpretation, will be futile without a deep understanding of the patient's life story and psychical reality.

In Social Suffering in the Sociology of Zygmunt Bauman, Michael Hviid Jacobsen explores how the theme of suffering has run through the works of the late Zygmunt Bauman. The article traces how we might understand suffering as an inherent part of human life, how it is both individual and general, and how it is unequally distributed. Jacobsen discusses how suffering and culture constitute the core of Bauman's body of work. The article then describes how Bauman focused on the change from what might be called solid-modern suffering to liquid-modern suffering. The former being a form of 
suffering that exists because of totalitarian tendencies and the latter a form of suffering that is much dispersed and intangible. Jacobsen also discusses some of Bauman's most famous work on globalization, including his concepts of tourists and vagabonds as winners and losers in the globalization game - as those who might suffer under these developments and those who might overcome suffering. The article ends with a discussion of what we should do to alleviate suffering, seen from Bauman's perspective. The question of our responsibility to the Other comes into the foreground and Bauman rests his notion of normativity in this responsibility - and thus asks us to make a difference in the world.

The article Narratives of Loss: Exploring Grief through Photography, written by Ignacio Brescó de Luna and Belén Jiménez-Alonso, likewise begins in cancer. The articles seek to expand the often exclusively verbal understanding of meaning-making central to bereavement. Photography is introduced, both as a methodological tool that might enrich our understanding of the temporality of grief, and a therapeutically fruitful tool. Through pictures, we get a glimpse of Maria's struggles following the loss of a close friend. Given the close proximity to cameras that today's use of cellphone offers, picture taking cannot be overlooked if we wish to understand contemporary technologies of the self. For bereaved people especially, picture taking offers an opportunity to show what cannot be expressed in words, remembering and honoring the dead in ways otherwise precluded. Researchers need to be, the writers argue, up to the timely task of navigating this field and grasp the opportunities offers by visual methods in general.

In Necessary Suffering? - Investigating Existential Suffering in Youth, Joachim Meier investigates everyday suffering among high school adults in Denmark. Drawing on qualitative interviews with people on the threshold to adulthood, he asks how their various sufferings should be understood. The article begins with a critical discussion of contemporary tendencies of pathologization, that Meier fears overshadows both the normative and contextual aspects of suffering. Under the rubric 'Existential suffering', Meier presents the difficulties of his informants in the light of freedom, anxiety, finitude and otherness. These types of sufferings that "cling to life", should be seen as an inevitable feature of existence itself, something that the (necessary) attempts to make a distinction between legitimate and illegitimate forms of suffering need to consider. The question of what kinds of suffering we should or should not bear, and to what extent being against suffering even makes 
sense, is a question that transcends the limits between the personal, cultural and existential dimensions of life.

In A Virtue Ethical Approach to Interpretation of the Suffering Other, Anne Eggert Stevns likewise begins with questions related to pathologization, asking whether the existential and ethical aspects of suffering are overshadowed by a reductive bio-medical framework. Framing the discussion within a practioner-client relationship, Stevns asks what a recognition of otherness consists in, and, conversely, what a treatment that respects the client as a meaning-making and agential person amounts to. Iris Murdoch's understanding of love as the selfless, and, to a certain extent, disinterested acknowledgement of the reality of the other as distinct from oneself becomes the key to an understanding of what it means to see the other as, namely, an other. The loving gaze that enable us see nature, art and literature as beauty beyond the self, could likewise, Stevns argue, guide our interpersonal and caring relationships as well.

In Negotiation languages of suffering in Northern Uganda, Lars Hedegaard Williams discusses suffering through the perspective of NGO's working in a post-conflict area of Northern Uganda, based on his fieldwork in the area. The article elaborates how there is an ongoing psychiatrisation and psychologization of the local cosmology, which then transforms local notions of suffering. Williams critiques the current view that all psychological notions of suffering from the Global North that are implemented in other contexts necessarily leads to a form of therapeutic governance - instead he argues that we should look at global culture as an ever-changing flow. Williams specifically looks at trauma and PTSD discourses in the wake of an armed conflict in Uganda and he argues that the use of diagnostic language by the NGO's working in the area does not replace or exclude the local cosmological understanding of suffering. Rather, it merges with local ideas into new forms and alternative ways of conceptualizing and perceiving illness, distress, trauma and suffering. Williams elaborates how trauma can take on different meanings: Either as interchangeable with PTSD, as a disorder brought on by spirits for moral reasons, as disorder brought by demons or the Devil or more as part of an illness-phase and something more diffuse. Williams argues for a more pragmatic concept of suffering - a concept of that is understood as something people do and use to cope with the world around them. 


\section{Acknowledgements}

This special issue has grown out of the research centre in The Culture of Grief. The editors remain much thankful for the opportunity of growing up academically in an environment where interdisciplinary is a language everyone speaks, and crossing disciplinary borders in is something that everyone does. We remain especially thankful to our supervisors, Anders Petersen and Svend Brinkmann for wholehearted support and encouragement throughout our time as Ph.D.-fellows. The Culture of Grief is financed by The Obel Family Foundation.

\section{References}

Barrister, L (2017). Enduring Time. Bloomsbury Publishing.

Bauman, Z. (1992). Mortality, Immortality, and other Life Strategies (1st ed.). Cambridge: Polity Press.

Berger, P., \& Luckmann, T. (1966). The Social Construction of Reality: A treatise in the sociology of knowledge(1st ed.). Retrieved from http://ideanetworking.com.au/docs/sensemaking/Peter_L._Berger_Thomas_Luckmann The_Social_Cons_BookFi.org_.pdf

Brinkmann, S., \& Petersen, A. (2015). Diagnoser - Perspektiver, Kritik og Diskussion (1st ed.). Aarhus: Forlaget Klim.

Butler, J. (2006). Precarious Life: The Powers of Mourning and Violence. London: Verso, 2006.

Hägglund, M. (2019). This Life : Secular Faith and Spiritual Freedom. New York: Pantheon Books, 2019.

Keohane, K., \& Petersen, A. (Eds.). (2013). The Social Pathologies of Contemporary Civilization (1st ed.). London: Routledge.

Lingis, A. (1994). The Community of Those Who Have Nothing in Common. Bloomington: Indiana University Press.

Løgstrup, K. E. (1997). The Ethical Demand. Notre Dame: University of Notre Dame Press.

Moore, J. W. (2017). The Capitalocene, Part I: on the nature and origins of our ecological crisis. The Journal of Peasant Studies, 44(3), 594-630.

Moore, J. W. (2018). The Capitalocene Part II: accumulation by appropriation and the centrality of unpaid work/energy. The Journal of Peasant Studies, 45(2), 237-279.

O'Byrne, A. (2010). Natality and Finitude. Bloomington: Indiana University Press. 
Rosa, H. (2015). Social Acceleration: A New Theory of Modernity (1st ed.). New York: Columbia University Press.

Rosa, H. (2019). Resonance: A sociology of our relationship to the world (1st ed.). John Wiley \& Sons.

The Culture of Grief, Project Description. Retrieved from: https://www.kommunikation.aau.dk/digitalAssets/268/268233 the-culture-of.grief.pdf

\section{About the Authors}

Alfred Bordado Sköld is a philosopher and psychologist, currently a Ph.D.-student at the research centre, The Culture of Grief. His dissertation, Relationality and Finitude - A Social Ontology of Bereavement, explore the existential and socio-ontological aspects of grief. Drawing on existential phenomenology, deconstruction, psychoanalytic theory, and a longitudinal interview study with bereaved life partners in different generations, he attempts to understand the coordinates of relationality in general, our notion of a shared life in particular, and how grief can inform and deepen our notions of mortality.

Peter Clement Lund is a sociologist and Ph.D.-student at Aalborg University and part of the research centre, The Culture of Grief, where he is researching the forthcoming diagnostic classification of Prolonged Grief Disorder. Using a combination of theoretical discussion and a qualitative methodology of gonzo sociology he investigates how our current culture exists in an ongoing struggle for the rights to define and treat grief as a phenomenon - and the consequences this has for our beingin-the-world. 